\title{
KEANEKARAGAMAN JENIS SEMUT (Formicidae) ARBOREAL DI HUTAN MANGROVE KELURAHAN SETAPUK BESAR KOTA SINGKAWANG
}

\author{
(Arboreal Ants Species Diversity In Mangrove Forest Of Setapuk Besar Singkawang City)
}

\author{
Mazlan, Siti Masitoh Kartikawati, Burhannudin \\ Fakultas Kehutanan Universitas Tanjungpura Pontianak. Jl. Daya Nasional Pontianak. \\ Maslan.bidosta@gmail.com
}

\begin{abstract}
Arboreal ants are ants that do activities and spend their lives in tree. Roles of this organism are to serve as decomposers, pollinators, predators and indicators. Ant species diversity constitutes a chain for ecosystem stability. They are responsible as decomposing insects making their presence becomes ecologically vital. Research on ant species diversity in mangrove forest remains insufficient. One of the reasons possibly is that fact that mangrove is an ecosystem which is affected by sea tide. This research aims at gathering data about ant species diversity based on types of mangrove forest vegetation located in Setapuk Besar, Singkawang City. The research used a survey method by observing types of trees whose diameter was $10 \mathrm{~cm}$ and above. Additionally, the tree should have a large number of ants. The data was collected through fly sheet trap set under, in the mid, and above the tidal level. Findings revealed 6 types of ants consisting 4 sub-families in 6 types of the trees i.e. Rhizopora mucronata, Avicennia lanata, Hibiscus tiliaceus, Terminalia capatta, Nypa fruticans, and Bruguiera cylindrical.. Based on the diversity index of those 6 types of trees, the divercity of arboreal ants spesies could be categorized low $\left(H^{\prime}<1\right)$. The highest diversity was nypa fruticans vegetation by 0.325 . This was because the tree contains sugar level and carbohydrate. The lowest diversity was Hibiscus tiliaceus and Termialia catappa. The H'value was 0 . One of the reasons was because only one species of ants can be found in both trees, namely Oecophylla smaragdina.
\end{abstract}

Keywords: Arboreal Ants, Diversity, Mangrove, Singkawang

\section{PENDAHULUAN}

Semut adalah serangga sosial yang merupakan kelompok serangga yang termasuk ke dalam ordo Hymenoptera dan famili Formicidae. Organisme ini terkenal dengan koloni dan sarangsarangnya yang teratur. Semut dibagi menjadi semut pekerja, pejantan dan ratu. Organisme ini memiliki kurang lebih 12.000 spesies yang tersebar di dunia, dan sebagian besar berada di kawasan tropis (Suhara, 2009).
Semut dapat digunakan sebagai salah satu bioindikator kondisi suatu ekosistem. Semut dan tanaman mempunyai hubungan timbal balik yang besar, tidak hanya memberikan pupuk tanaman dengan nutrisi penting, tetapi kadang-kadang juga berfungsi sebagai penyerbuk (Schultz and McGlynn, 2000). Beberapa peranan dari organisme ini adalah sebagai dekomposer, penyerbuk, membuat aerasi tanah, predator dan indikator (Tawatao, 2014). Peranan yang cukup 
banyak organisme ini hampir tersebar disemua habitat salah satunya adalah pada ekosistem mangrove (Cole, 1983). Semut memiliki beberapa peranan pada ekosistem ini diantaranya adalah sebagai penyerbuk, predator, hama, pengurai dan herbivora (Abtar et al., 2013).

Hutan mangrove yang ada di Kelurahan Setapuk Besar berdiri pada tahun 2009-2010. Luas wilayah mangrove yang dikelola mencakup keseluruhan wilayah pesisir Kelurahan Setapuk Besar Kota Singkawang. Berdasarkan ploting area yang dilakukan oleh Badan Lingkungan Hidup Kota Singkawang total luasan areal pengelolaan mangrove yaitu \pm 20 , 6763 ha. Kawasan mangrove tersebut didominasi oleh tumbuhan jenis Rhizophora mucronata, Avicennia lanata, Hibiscus tiliaceus, Terminalia Catappa, Ceriops spp, Nypa Fruticans, Bruguiera cylindrica dan Sonneratia spp dengan beberapa jenis fauna yang beragam salah satunya semut.

Penelitian tentang keanekaragaman jenis semut di kawasan hutan mangrove yang masih sangat sedikit dilakukan. Oleh karena itu penelitian keanekaragaman semut di kawasan hutan mangrove di khususkan untuk jenis semut arboreal berdasarkan jenis vegetasi. Penelitian ini bertujuan untuk memperoleh data keanekaragaman jenis semut berdasarkan jenis vegetasi hutan mangrove. Manfaat penelitian yaitu untuk dapat memberikan informasi mengenai keanekaragaman jenis semut dalam perkembangan ilmu pengetahuan dan upaya peletarian pada hutan mangrove di Kelurahan Setapuk Besar Kota Singkawang.

\section{METODE PENELITIAN}

\section{Pengumpulan Data}

Pengambilan data ini dilaksanakan pada hutan mangrove di Kelurahan Setapuk Besar, Kecamatan Singkawang Utara Kota Singkawang. Penelitian dilakukan dengan waktu \pm tiga minggu efektif dilapangan. Alat-alat yang digunakan dalam penelitian ini adalah: peta lokasi, GPS (Global Positioning System), fly sheet (kertas lem), penjepit kecil atau forceps, kamera, alat tulis menulis, botol sampel, blanko sampel, kaca pembesar atau lup, meteran, thermo higrometer dan tangga. Bahanbahan yang digunakan dalam penelitian ini adalah: sampel semut sebagai objek penelitian, alkohol $70 \%$ dan gula pasir dan ikan untuk umpan pada jebakan.

Peletakan jebakan ditetapkan berdasarkan pertimbanganpertimbangan dengan memperhatikan kondisi fisik dan biologis yang mempengaruhi keberadaan semut di lapangan. Peletakan jebakan dilakukan secara sengaja (purposive sampling) berdasarkan jenis vegetasi mangrove yang mempunyai diameter $10 \mathrm{~cm}$ (tingkat pohon) dan memilih pohon yang terdapat semut (Gambar 1). Berdasarkan hasil survey prapenelitian jenis vegetasi tersebut adalah Rhizophora mucronata, Avicennia lanata, Hibiscus tiliaceus, Terminalia catappa, Nypa fruticans, dan Bruguiera cylindrica. 
Peletakan jebakan yaitu terdiri atas; strata bawah, yaitu fly sheet diletakan pada batas tertinggi air pasang, strata tengah pohon yaitu fly sheet diletakan pada batang bagian tengah pohon, strata atas pohon yaitu fly sheet diletakan pada bagian atas pohon.

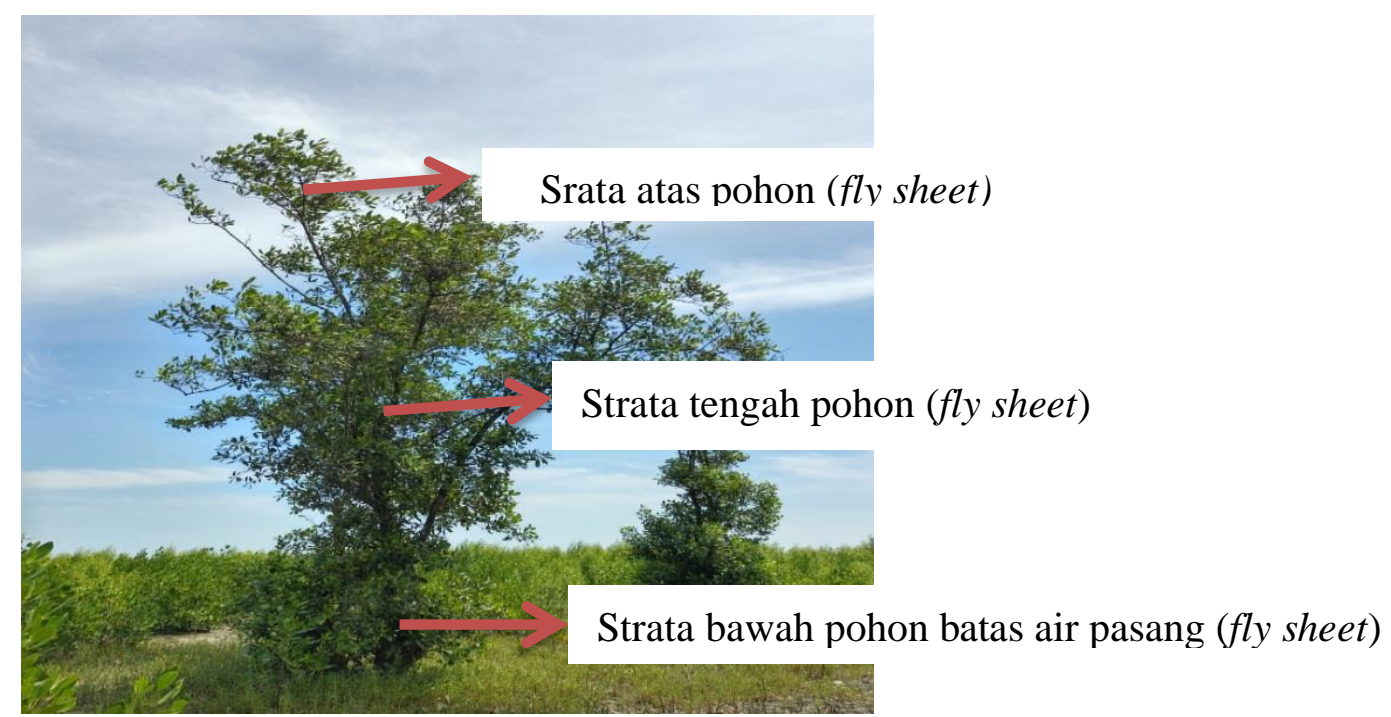

Gambar 1. Peletakan Jebakan Pada Setiap Jenis Vegetasi (Laying Traps In Each Species Vegetation)

Setelah perangkap dipasang, dan Analisa Data Keanekaragaman selanjutnya tinggal melakukan pengontrolan atau pemeriksaan perangkap tersebut untuk mengambil semut yang telah terperangkap pada jebakan. Penangkapan semut dilakukan dengan 3 kali ulangan pada setiap jenis vegetasi. Kemudian semut yang telah tertangkap dimasukan kedalam botol sampel yang telah berisi alkohol dengan menggunakan penjepit kecil atau pinset dengan tujuan untuk mengawetkan semut agar tidak rusak.

\section{Analisis Data}

Data hasil pengamatan yang didapatkan di lapangan akan dianalisa secara deskriptif yaitu: Analisis Jenis Semut, Analisis pH dan Salinitas Jenis.

1. Indeks Keanekaragaman Jenis/ Spesies (Shannon Wiener), Untuk mengetahui keanekaragaman jenis berdasarkan kelimpahan jenisnya (Magurran,1998) dengan persamaan sebagai berikut;

Rumus : $\mathrm{H}^{\prime}=-\Sigma \mathrm{Pi} \ln \mathrm{Pi}$

Dimana :

$\mathrm{Pi}=$ Nilai Kelimpahan Semut

$\mathrm{H}^{\prime}=$ Keanekaragaman Jenis

$\mathrm{Pi}=n \mathrm{n} / \mathrm{N}$

Dimana :

ni $=$ Jumlah Individu Suatu Jenis Ke-i

$\mathrm{N}=$ Total Jumlah Individu

Dengan Kriteria: 


\begin{tabular}{ll}
\hline Kategori & Nilai \\
Rendah & $<1$ \\
Sedang & $1-3$ \\
Tinggi & $>3$ \\
\hline
\end{tabular}

2. Indeks Kekayaan Jenis (DMg)

Perhitungan ini dimaksudkan untuk mengetahui pola penyebaran jenis dari suatu komunitas dengan rumusan margalef (Magurran, 1983):

\footnotetext{
Rumus : $\mathrm{DMg}=(\mathrm{S}-1) / \ln \approx \mathrm{N}$

Dimana:

$\mathrm{S}=$ Jumlah Jenis

$\mathrm{N}=$ Jumlah Individu Seluruh Jenis

Dengan kriteria

$\mathrm{DMg}<2,5$ tingkat kekayaan rendah $2,5>\mathrm{DMg}>4$ tingkat kakayaan sedang

$\mathrm{DMg}>4 \quad$ tingkat kekayaan tinggi
}

3. Indeks Kemerataan Jenis

Merupakan

kemerataan

perbandingan individu yang merata dalam suatu komunitas (Magurran, 1988):

Rumus: $\mathrm{E}=\left(\mathrm{H}^{\prime}\right) / \ln \mathrm{S}$

Dimana:

$\mathrm{H}^{\prime}=$ Indeks Keanekaragaman Jenis/Spesies

$\mathrm{S}=$ Jumlah Jenis

Apabila nilai $\mathrm{E}<0,20$ dapat dikatakan kondisi penyebaran jenis tidak stabil, sedangkan apabila nilai $\mathrm{E} 0,21 \leq \mathrm{E} \leq$ 1dapat dikatakan kondisi penyebaran jenis stabil.

\section{Indeks Similaritas (IS)}

Indeks similaritas (IS) dihitung dengan rumus Similaritas Jaccards (Barbour et al., 1987) berikut:
Rumus : IS $=\frac{c}{a+b-c} \times 100$

Dimana:

$\mathrm{a}=$ Jumlah jenis yang hanya dijumpai pada vegetasi Rhizophora mucronata

$\mathrm{b}=$ Jumlah jenis yang hanya terdapat pada vegetasi Avicennia lanata

$\mathrm{C}=$ Jumlah jenis yang hanya terdapat pada vegetasi Rhizophora mucronata dan Avicennia lanata.

Kriteria indeks kesamaan jenis

$\begin{array}{ll}81-100 \% & \text { kategori tinggi } \\ 61-80 & \text { kategori sedang } \\ 41-60 & \text { kategori rendah } \\ <40 \% & \text { kategori sangat rendah }\end{array}$

\section{HASIL DAN PEMBAHASAN}

Berdasarkan hasil penelitian yang dilakukan di kawasan hutan mangrove pada 6 jenis tumbuhan mangrove yang berbeda yaitu Rhizophora mucronata, Avicennia lanata, Hibiscus tiliaceus, Terminalia catappa, Nypa fruticans, dan Bruguiera cylindrica ditemukan 6 jenis semut yang terdiri dari 4 sub famili yaitu 3 jenis dari sub famili Formicinae, 1 jenis dari sub famili Myrmicinae, 1 jenis dari sub famili Dolichoderinae dan 1 jenis dari sub famili Ponerinae yang terdiri dari 2349 individu semut yaitu, sub famili Formicinae 1780, sub famili Myrmicinae sebanyak 561 individu, sub famili Dolichoderinae 7 individu dan sub famili Ponerinae 1 jenis individu. Daftar jumlah spesies dan individu semut arboreal yang ditemukan pada 6 jenis pohon mangrove di Kelurahan Setapuk Besar Kota Singkawang dapat dilihat pada tabel 1 . 
Tabel 1. Jenis dan Perhitungan Indeks Keanekaragaman Jenis Semut Arboreal yang Ditemukan di Lokasi Penelitian (Species and calculation of the diversity index of arboreal ants that found at the study site)

\begin{tabular}{|c|c|c|c|c|c|c|c|}
\hline No & Nama Pohon & Nama Imiah Semut & $\begin{array}{l}\text { Jumlah } \\
\text { individu }\end{array}$ & pi & $\mathbf{H}^{\prime}$ & DMg & e \\
\hline \multirow[t]{3}{*}{1} & Avicennia lanata & Crematogaster sp & 357 & 0,95 & 0,02 & 12,8 & 0,01 \\
\hline & & Companotus consobrinus & 17 & 0,05 & 0 & 6,15 & 0 \\
\hline & Jumlah & & 374 & 1 & $\mathbf{0 , 0 2}$ & 18,9 & $\mathbf{0 , 0 1}$ \\
\hline \multirow[t]{5}{*}{2} & Bruguiera cylindrica & Crematogaster sp & 145 & 0,89 & 0,05 & 10,8 & 0,02 \\
\hline & & Companotus consobrinus & 15 & 0,09 & 0,1 & 5,88 & 0,08 \\
\hline & & Oecophylla smaragdina & 1 & 0,01 & 0,01 & 0 & 0 \\
\hline & & Dolichoderus thoracicus & 2 & 0,04 & 0,05 & 1,51 & 0,17 \\
\hline & Jumlah & & 163 & 1 & 0,21 & 18,2 & 0,27 \\
\hline \multirow[t]{6}{*}{3} & Nypa fruticans & Odontomachus sp & 1 & 0 & 0,01 & 0 & 0 \\
\hline & & Companotus consobrinus & 163 & 0,71 & 0,1 & 11,1 & 0,05 \\
\hline & & Crematogaster sp & 56 & 0,25 & 0,15 & 8,74 & 0,09 \\
\hline & & Polyrhachis sp & 3 & 0,01 & 0,02 & 2,39 & 0,05 \\
\hline & & Dolichoderus thoracicus & 5 & 0,02 & 0,04 & 3,49 & 0,05 \\
\hline & Jumlah & & 228 & 1 & $\mathbf{0 , 3 3}$ & 25,7 & 0,24 \\
\hline \multirow[t]{2}{*}{4} & Hibiscus tiliaceus & Oecophylla smaragdina & 166 & 1 & 0 & 11,1 & 0 \\
\hline & Jumlah & & 166 & 1 & $\mathbf{0}$ & 11,1 & $\mathbf{0}$ \\
\hline \multirow[t]{2}{*}{5} & Terminalia catappa & Oecophylla smaragdina & 376 & 1 & 0 & 12,9 & 0 \\
\hline & Jumlah & & 376 & 1 & $\mathbf{0}$ & 12,9 & $\mathbf{0}$ \\
\hline \multirow[t]{3}{*}{6} & Rhizophora mucronata & Companotus consobrinus & 1039 & 1 & 0 & 15,1 & 0 \\
\hline & & Crematogaster sp & 3 & 0 & 0,01 & 2,39 & 0,02 \\
\hline & jumlah & & 1042 & 1 & $\mathbf{0 , 0 1}$ & 17,5 & $\mathbf{0 , 0 2}$ \\
\hline
\end{tabular}

Berdasarkan hasil penelitian jumlah spesies terbanyak adalah dari sub famili Formicinae yaitu 3 spesies. Jenis semut yang paling banyak pada subfamili Formicinae adalah jenis semut Componotus consobrinus yaitu 1234 individu. Semut jenis ini adalah semut gula yang ditemukan pada pohon Nypa fruticans dan Rhizophora mucronata. Jenis Odontomachus sp hanya ditemukan 1 individu dikarenakan semut jenis ini adalah semut teresterial yang hidup di lantai hutan, di antara serasah daun atau di dalam kayu yang lapuk.

Tabel 1 menunjukkan bahwa keanekaragaman jenis (H') semut arboreal pada hutan mangrove Kelurahan Setapuk Besar tergolong rendah $\left(\mathrm{H}^{\prime}<1\right)$. Keanekaragaman semut tertinggi yaitu pada vegetasi Nypa fruticans sebesar 0,325, hal ini dikarenakan pada pohon Nypa fruticans mengandung kadar gula dan karbohidrat (Heriyanto et al., 2011). Vegetasi Hibiscus tiliaceus dan Terminalia catappa nilai $\mathrm{H}^{\prime}$ adalah 0 . Hal ini 
dikarenakan pada pohon Hibiscus tiliaceus dan Terminalia catappa hanya terdapat satu jenis semut yaitu Oecophylla smaragdina.

Kekayaan Jenis (DMg) semut arboreal pada hutan mangrove yaitu tergolong tinggi $(>4)$. Kekayaan jenis semut tertinggi yaitu pada vegetasi Nypa fruticans sebesar 25,682, hal ini dikarenakan pada pohon Nypa fruticans lebih banyak semut yang ditemukan. Kekayaan jenis semut terendah yaitu pada vegetasi Hibiscus tiliaceus sebesar 11, 1005. Hal ini dikarenakan jenis dan jumlah individunya sedikit ditemukan.

Indeks kemeratan jenis semut arboreal pada hutan mangrove yaitu Bruguiera cylindrica sebesar 0,274, dan
Nypa fruticans sebesar 0,237. Hal ini dikarenakan pada kedua pohon ini Keanekaragaman Jenis ( $\left.\mathrm{H}^{\prime}\right)$ lebih tinggi dari pohon yang lainnya dan pada pohon ini jumlah individunya lebih merata dan dapat dikatakan bahwa pada kedua jenis pohon ini kondisi penyebaran jenisnya stabil (E 0,21 $\leq \mathrm{E}$ $\leq$ 1). Sedangkan pada pohon Rhizophora mucronata nilai kemerataannya sebesar 0,016, Avicennia lanata 0,008, Hibiscus tiliaceus 0 , dan Terminalia catappa 0 , dikarenakan Keanekaragaman Jenis semut (H') sangat rendah (0) dan hanya terdapat satu jenis. Dapat dikatakan bahwa pada keempat pohon ini kondisi penyebarannya tidak stabil $(<0,20)$.

Tabel 2. Indeks Kesamaan Jenis (IS) Semut Arboreal Yang Ditemukan di Lokasi Penelitian (Similarity Index of species (IS) of Arboreal Ants Found at Research Sites)

\begin{tabular}{|c|c|c|c|c|c|c|}
\hline & $\mathrm{a}$ & B & $\mathrm{C}$ & $\mathrm{d}$ & $\mathrm{e}$ & $\mathrm{F}$ \\
\hline A & & $100 \%$ & $50 \%$ & $40 \%$ & $0 \%$ & $0 \%$ \\
\hline B & & & $50 \%$ & $40 \%$ & $0 \%$ & $0 \%$ \\
\hline $\mathrm{C}$ & & & & $28,58 \%$ & $25 \%$ & $25 \%$ \\
\hline $\mathrm{D}$ & & & & & $0 \%$ & $0 \%$ \\
\hline $\mathrm{E}$ & & & & & & $100 \%$ \\
\hline $\mathrm{F}$ & & & & & & \\
\hline
\end{tabular}

Keterangan: $\mathrm{a}=$ Rhizophora mucronata $\mathrm{b}=$ Avicennia lanata $\mathrm{c}=$ Bruguiera cylindrica $\mathrm{d}=$ Nypa fruticans $\quad e=$ Hibiscus tiliaceus $\mathrm{f}=$ Terminalia catappa 
Kriteria indeks kesamaan jenis yaitu $81-100 \%$ kategori tinggi, 61-80 kategori sedang, 41-60 kategori rendah, $<40 \%$ kategori sangat rendah.

Berdasarkan tabel 2 di atas dapat diketahui bahwa semut arboreal yang tingkat kesamaan jenisnya tinggi yaitu antara Rhizophora mucronata dan Avicennia lanata (ab) serta Hibiscus tiliaceus dan Terminalia catappa (ef) yaitu $100 \%$. Hal ini dikarenakan jenis semut yang ditemukan pada pohon Rhizophora mucronata dan Avicennia lanata serta Hibiscus tiliaceus dan Terminalia catappa terdapat kesamaan jenis. Semut pada pohon Rhizophora mucronata dan Hibiscus tiliaceus (ae), Rhizophora mucronata dan Terminalia catappa (af), Avicennia lanata dan Hibiscus tiliaceus (be), Avicennia lanata dan Terminalia catappa (bf), Nypa fruticans dan Hibiscus tiliaceus (de), Nypa fruticans dan Terminalia catappa (df) tingkat kesamaannya sangat rendah yaitu $0 \%$. Hal ini disebabkan karena walaupun jumlah individu jenisnya banyak namun spesiesnya berbeda.

\section{KESIMPULAN}

Berdasarkan hasil penelitian tentang keanekaragaman jenis semut arboreal di kawasan hutan mangrove kelurahan setapuk besar kota singkawang ditemukan 6 spesies semut yang terdiri dari 4 sub famili yaitu 3 jenis dari sub famili Formicinae, 1 jenis dari sub famili Myrmicinae, 1 jenis dari sub famili Dolichoderinae dan 1 jenis dari sub famili ponerinae. Terdiri atas 2349 individu semut yaitu, sub famili Formicinae 1780, sub famili Myrmicinae sebanyak 561 individu, sub famili Dolichoderus 7 individu dan sub famili ponerinae 1 jenis individu, dimana masing-masing didapatkan dengan cara memasang perangkap (Fly Sheet) dengan 3 strata yaitu strata bawah batas tertinggi air pasang, strata tengah dan strata atas.

Keanekaragaman Jenis (H) semut arboreal pada Hutan Mangrove yaitu Nypa fruticans lebih besar yaitu sebesar 0,325, sedangkan pada pohon Hibiscus tiliaceus dan Terminalia catappa sangat randah yaitu 0. Dilihat dari semua jenis pohon maka keanekaragaman jenis semut pada hutan mangrove tergolong rendah.

Semut merupakan salah satu jenis serangga sosial yang memiliki keunikan serta jenis yang beragam dalam ekosistem, diharapkan kepada pihak pengelola Hutan Mangrove Di Kelurahan Setapuk Besar Kota Singkawang dapat bekerjasama dengan masyarakat untuk menjaga kelestarian kawasan tersebut demi terciptanya kestabilan ekosistem sehingga keberadaan serangga ini dapat dipertahankan.

Melihat dari keunikan serta manfaatnya hendaknya dilakukan penelitian dan kajian lebih mendalam tentang semut arboreal ini agar keberadaan serangga ini tidak sematamata hanya dipandang sebagai serangga perusak tetapi sebaliknya serangga ini dapat dimanfaatkan sebagai serangga pembasmi hama karena sifatnya sebagian besar adalah karnivora.

\section{DAFTAR PUSTAKA}

Abtar, Hasriyanti dan Burhanuddin, N. 2013. Komunitas Semut 
(Hymenoptera: Formicidae) pada Tanaman Padi, Jagung, dan Bawang Merah. Jurnal Agrotenologi dan Bisnis1(2): 109112.

Barbour, G.M., J.K. Burk and W.D. Pitts. 1987. Terrestrial Plant Ecology.

Cole, b.j, (1983). Assembly of mangrove ant communities: patterns of geographical distribution. Journal of animal ecology, 52, 339-347.

Heriyanto,N.M., Subiandono E.dan Karlina E. 2011. Potensi dan sebaran Nipah (Nypa fruticans) sebagai sumber daya pangan. Jurnal penelitian hutan dan konservasi alam. Vol.8 No.4 : 327 -335 .

Jumadi. 2009. Penerimaan Nominasi Kalpataru Dinas Kelautan pontianak. Singkawang.

Magurran A. 1988. Ecologycal Diversity and Its Measurement. Princeton University Press. American.
Schultz, t. R. And mcglynn, t. P. 2000. The interaction of ant with other organim./ In: agoeti, d., majer, j., alonso, e. Et al. (ads), ants: tandard methods for measuring and monitoring biodiversity. Smithsonian institution press, $\mathrm{pp}$. $35-/ 44$.

Suhara. 2009. Semut Rangrang (Oecophylla smaradigna). http://file.upi.edu/Direktori /FPMIPA/JUR._PEND.BIOLOGI /196512271991031-

SUHARA/Semut-Rangrang PPT_Entomologi.pdf. Diakses: 27 Juli 2014.

Syafei, E.S. 1994. Ekologi Tumbuhan. Bandung: Institut Teknologi Bandung.

Tawatao, N.B. 2014. Basic Biology and Ecology of Ants. http://www.antbase.net/english/an ts-of-southeastasia/ecology/basic-antbiology. html. Diakses: 20 Agustus 2014. 